\title{
CORRESPONDENCE
}

\section{Powerful Knowledge with Geography}

\author{
Nimal Dangalle \\ Professor Emeritus \& former Chair Professor, Department of Geography, Faculty of Social Sciences, University of Kelaniya, Kelaniya, Sri Lanka.
}

During the past 50 years or so the subject of geography in the school curriculum in Sri Lanka has been subject to various interventions and misplacements, raising doubts among its practitioners of their discipline's position in school education. The fact is, although almost everyone endorses the importance and relevance of geography, no one wants to house it in due place in school curriculum. Further, a question often raised by planners is what can geography students do after they finish their school education? Such underestimations have not been limited only to Sri Lanka but also seen even in countries like the USA. Perhaps, geographers themselves should equally bear the responsibility for this unsatisfactory state of affairs. In large measure, we all have forgotten to unravel what is in 'geography store' that could justify its due place.

It is argued here that school geography in Sri Lanka, for that matter even academic geography taught in the university, should be able to produce students with 'powerful knowledge'. The ingredients of powerful knowledge are available in the geography store and it is up to the practitioners in the discipline to unearth them and integrate into the curriculum. Sri Lanka needs human resources with powerful geography knowledge, who can visualise, conceptualise, explain, analyse and find solutions to issues in different contexts.

The concept of powerful knowledge was first introduced into school educational debate by Michael
Young, a British sociologist (Young, 2008). According to Young,

"Powerful knowledge refers to what the knowledge can do or what intellectual power it gives to those who have access to it. Powerful knowledge provides more reliable explanations and new ways of thinking about the world and acquiring it and can provide learners with a language for engaging in political, moral, and other kinds of debates." (Young, 2008: p. 20)

The concept of powerful knowledge in education has been discussed in relation to geography in many contexts (see, Maude, 2015; Biddulph et al., 2020). Maude, writing on powerful knowledge in geography in the context of Australian school curriculum made the following observation:

"It is an idea that could be of value in school geography. ...It might help students to see some structure and order in our subject, rather than a mass of unconnected information. ...It could be a way of explaining to others what geography is about, and how it adds to school education because of the distinctive and significant knowledge it teaches..." (Maude, 2015: p. 18)

The discipline of geography is in an advantageous position to adopt the concept of powerful knowledge

"Corresponding author (dangalle1946@yahoo.co.uk; (iD https://orcid.org/0000-0003-0873-7261) 
for obvious reasons. Owing to the possession of a set of key concepts that help students to conceptualise and contextualise the phenomena they study, the subject of geography paves way to strengthen their thinking power. Even a cursory look at a definition of geography would point to the subject's capacity in producing students with powerful knowledge.

Geography is a discipline that describes, explains, analyses, interprets and contextualises the character of the landscape of places - the composite expression of the interplay between physical bases and human activities -employing the concepts of place, space, interconnectedness, movements, time, scale and change.

It is argued here that to produce students with powerful knowledge, it is essential to design concept-based curricula. At present, however, the attention has largely been on content-focused curricula but their contribution to produce students with powerful knowledge is limited. Content-focused curricula in Sri Lanka, not only in geography but also in many other social science subjects, have many shortcomings. A major problem is the continuous expansion in the boundaries of the subject as new paradigms emerge and the accumulation of new content material. As a result, what students learn at school soon become outdated and by the time they enter the world of work, the subject matter they learned will be historical. On the other hand, it is not so sure that the new knowledge reach the schools in an egalitarian manner. Often, many geography teachers in Sri Lanka, complain that their students, especially in rural areas, are not in a position to acquire new and updated knowledge on the subject. There is the delimitation problem of the subject content, also. In Sri Lanka, it has been the experience with curriculum planning exercises that it is difficult to arrive at a consensus on what to include in the content. It has been the practice to feed students with heavy loads of information irrespective of their absorption capacity. Another problem arises at the delivery level, too. In Sri Lanka, the education has become very competitive and especially at the GCE Advanced Level the competition is acute. The places available in the universities are limited and only the students who score highest marks will succeed. As such, teachers tend to feed their students with more and more subject content, irrespective of the limits shown in learning outcomes in the curriculum. An added problem is that many teachers, being university graduates, tend to teach what they learned at the university to their students with the sincere hope that their students will be in an advantageous position at public examinations. Another problem is the disagreements that occur among subjects in social sciences regarding the ownership of the subject matter. Subject specialists often complain that their subject matter is taught in other subjects and there is a problem of trespassing.

A set of basic concepts in geography, if used rationally, would make geography a vehicle for acquiring powerful knowledge.

Place is the most fundamental but a far-reaching and powerful concept in geography. In any definition of geography the identification, explanation, analysis and interpretation of the character of place is emphasised as the core of the discipline. Studying a place provides an entry point to step into a complex world waiting to be understood. In geography, place is considered as an object of thought rather than an object of study. By being an object of thought it promotes students' thinking and conceptualising power.

Character of a place is determined, among other things, primarily by its location. Sri Lanka could be taken as an example. Its absolute location would determine the physical characteristics like weather and climate, vegetation and soils and a host of other environmental traits. At the same time, its relative location has been instrumental in shaping, in addition to physical characteristics, the island's human geographical character. For instance, the location of Sri Lanka in the Indian Ocean in close proximity to the sub-continent has resulted in shaping the island's demographic, cultural, and political and many other characteristics of continuing significance. Also, due to its location along the east-west sea routes, the island was subject to foreign invasions, occupations and interventions, resulting in opening up the island to the outer world, thereby paving way to changes in its economy, trade and politics, the consequence of which could be seen even at present. Student understanding of these dynamics would provide a basis for thinking beyond particular contexts and transfer their conceptualising skills to other situations.

Space is another concept in geography that enables students to think, deeply and powerfully, on how space is organised by the society, how those spatial arrangements have produced specific patterns, relationships and interactions at varying scales and to examine the impacts of those relationships on people and their environment. The consequences of spatial relationships and interactions are of much relevance in the present context of advancing globalisation. Also, the ravaging COVID-19 pandemic is an eye-opener to rethink how spatial relationships could be so decisive on the fate of the millions of people of the world.

The components of a spatial entity are not static. They tend to interact with each other resulting in 
various relationships. For example, cities would establish relationships with the hinterland for their food requirements and people in the hinterland would rely on cities for various services like education and health and other necessities of modern life. However, a particular spatial entity will not remain in isolation long but will start establishing relationships with other entities in order to satisfy the increasing demands of its people. The process will result in a multitude of interactions involving people, goods and ideas. People will migrate from one place to another affecting both origins and destinations, goods will be distributed from centres of production to centres of consumption and new ideas of technology will be transferred from one place to another transforming the economic, social and cultural landscapes of places. However, these spatial relationships have, in some instances, negative effects on people, places and environment. As Maude points out,

"spatial distributions are worth understanding because they have consequences, a point that is often neglected in school geography curriculums and textbooks. Students are frequently asked to explain a spatial distribution, but less frequently to think about its consequences, so they don't get to understand the environmental, economic, social or political significance of a spatial pattern" (Maude, 2015).

Environment is another concept in geography that encourages students to take an active role in an area which is of critical importance at present. More than ever in history, we see, hear and experience how biophysical environment is threatening human survival through poor quality air, polluted water and degraded agricultural land and other forms of natural disasters. Especially since the second half of the $20^{\text {th }}$ century, people have begun to pay attention to their biophysical environment in an organised manner through the establishment of global level institutions to deal with environmental issues and problems.

In geography, students are taught on the reciprocal relationship between man and his biophysical environment in considerable detail. They learn how man is dependent on environment for resources and services that support his life. They also study the dynamics of various processes at work in producing those resources. They will critically examine how the increasing demand caused by expanding population and rising living standards of people exert pressure on environmental resources, resulting in various problems. They understand the necessity of maintaining a balance between demand and supply in order to sustain human life and would begin push-through their views on a range of environmental issues and problems.

No place on the earth's surface lies in isolation. They are interconnected. Perhaps it may be of relevance to recall Waldo Tobler's First Law of Geography: 'everything is related to everything else'. Interconnection lies at the top of the hierarchy of concepts because it incorporates many other concepts such as location, place, space, scale, time and so on. It becomes powerful not only because of its richness as a concept but also because of its explanatory power. It equips students with skills to view a place from a holistic perspective. Students will be able to visualise and interpret the character of a place paying attention to the context within which it behaves.

Interconnection operates through movements of people, products and capital. With advancing globalisation and information and communication technology, the pace of movements has increased as never before and accordingly, that of interconnections. As evident from COVID-19 pandemic, the movement of people would result in spreading diseases at varying scales, local, regional and global. Movement of products, through trade and transport, has connected distant places, thereby changing consumption patterns of the people and economic structures of the countries. However, as far as the transformation of the landscapes of places is concerned, it is information and communication technology that has paved way for far reaching effects. The movement of capital, as evident from the plantation agriculture and mining industries in South Asia, Southeast Asia and Africa has travelled across oceans producing alien economies in the colonies. A study of these relationships, as Doreen Massey says, gives 'sense of how any particular place and it relations fit into the bigger picture.' The ability to view the bigger picture is a special skill that a geography student possesses.

\section{REFERENCES}

Maude, A. (2015) What is Powerful Knowledge and Can It Be Found in the Australian Geography Curriculum?, Geographical Education, 28(18), pp:18-26.

Young, M. (2010) The future of education in a knowledge society: The radical case for a subject-based curriculum, Journal of the Pacific Circle Consortium for Education, 22(1), pp: 21-32. 